\title{
EDUCAÇÃO FÍSICA NA EDUCAÇÃO INFANTIL: PROPOSTA INTERDISCIPLINAR DE ATIVIDADES CIRCENSES
}

\author{
Laís Marconato Corsi \\ Universidade Estadual de Campinas, Campinas, São Paulo, Brasil \\ Ademir De Marco \\ Universidade Estadual de Campinas, Campinas, São Paulo, Brasil \\ Teresa Ontañón \\ Universidade Estadual de Campinas, Campinas, São Paulo, Brasil
}

\begin{abstract}
Resumo
Este estudo teve por objetivo estruturar uma proposta pedagógica interdisciplinar com foco no universo circense, contemplando algumas de suas atividades e aproximando a educação infantil à arte, à cultura, ao movimento, à expressão e ao lúdico. O estudo consistiu em pesquisa qualitativa, com caráter descritivo e do tipo documental, pois buscou estabelecer relações baseadas em fontes diversas. O texto apresenta possibilidades de trabalho pedagógico com as atividades circenses na educação infantil, no intuito de despertar para o planejamento elaborado com estratégia interdisciplinar, na qual participem pedagogas, professores de Educação Física e de demais áreas do conhecimento humano que possam contribuir com o desenvolvimento integral das crianças participantes.

Palavras-chave: Educação física. Educação Infantil. Interdisciplinaridade. Atividades Circenses.

\section{PHYSICAL EDUCATION IN EARLY CHILDHOOD EDUCATION: INTERDISCI- PLINARY PROPOSAL OF CIRCUS ACTIVITIES}

\begin{abstract}
This study aimed to structure an interdisciplinary pedagogical proposal focused on the circus universe, contemplating some of its activities and bringing Child Education closer to art, culture, movement, expression and ludic. The study consisted of qualitative research, with a descriptive character and the documentary type, since it sought to establish relationships based on diverse sources. The text presents possibilities of pedagogical work with the circus activities in Early Childhood Education, in order to awaken to the planning elaborated with interdisciplinary strategy, in which pedagogues, Physical Education teachers and other areas of human knowledge can contribute to the integral development of the participating children.

Keywords: Physical Education. Early Childhood Education. Interdisciplinarity. Circus Activities.
\end{abstract}




\title{
EDUCACIÓN FÍSICA EN LA EDUCACIÓN INFANTIL: PROPUESTA INTERDIS- CIPLINAR DE ACTIVIDADES CIRCENSES
}

\begin{abstract}
Resumen
Este estudio tuvo por objetivo estructurar una propuesta pedagógica interdisciplinar enfocada en el universo circense, contemplando algunas de sus actividades y aproximando la Educación Infantil al arte, a la cultura, al movimiento, a la expresión y al lúdico. El estudio consistió en investigación cualitativa, con carácter descriptivo y del tipo documental, ya que buscó establecer relaciones basadas en fuentes diversas. El texto presenta posibilidades de trabajo pedagógico con las actividades circenses en la Educación Infantil, con la intención de despertar para la planificación elaborada con estrategia interdisciplinar, en la que participen pedagogas, profesores de Educación Física y de otras áreas del conocimiento humano que puedan contribuir con el desarrollo integral de los niños participantes.
\end{abstract}

Palabras claves: Educación Física. Educación Infantil. Interdisciplinaridad. Actividades Circenses.

\section{Introdução}

Neste estudo, realizado no âmbito da Educação Física, o movimento humano é compreendido como linguagem, como capacidade expressiva, o que cria a possibilidade da apropriação crítica do conteúdo e da ressignificação da prática corporal. Esta é a concepção de movimento humano que acreditamos e que norteia esta proposta, a sua compreensão como linguagem e que, portanto, é criadora e ao mesmo tempo produto da cultura (SANTIN, 2003). Nesse sentido, o conteúdo da Educação Física escolar não é a educação do corpo, mas sim o conhecimento da cultura corporal, que busca compreender a expressão corporal como uma linguagem, problematizando as diferentes atividades expressivas corporais como dança, ginástica, capoeira, esporte e jogos (COLETIVO DE AUTORES, 1992) e, neste caso, o circo.

A educação infantil, incluída como parte da educação básica brasileira a partir da Lei de Diretrizes e Bases da Educação (LBDEN) nº 9.394 (BRASIL, 2010), permitiu superar a dicotomia com relação à educação de crianças pequenas até então. A partir desse período, a criança passa a ser compreendida como "um sujeito de direitos, que necessita ser educada e cuidada, uma vez que depende dos adultos para sobreviver" (CERISARA, 1999, p.16). Nesse sentido, diz-se que o cuidar e o educar na educação infantil são indissociáveis (AYOUB, 2001). Desse modo, a educação infantil não se organiza de forma fragmentada, por disciplinas. Isso porque um processo educativo fragmentado, modelo da escola tradicional - dos níveis subsequentes -, tem um caráter de especialização do conhecimento (THIESEN, 2008), enquanto o desenvolvimento do trabalho pedagógico na educação infantil deve acontecer de forma integral, em suas dimensões "expressivo-motora, afetiva, cognitiva, linguística, ética, estética, política e sociocultural” (BRASIL, 2010, p. 19).

Um modelo de trabalho pedagógico interdisciplinar, principalmente na educação infantil, atende às especificidades desse primeiro nível da educação básica. Um processo educativo interdisciplinar que busca romper com a especialização permite a formação total do ser humano, inserido em sua realidade e como agente das mudanças do mundo, possibilitando que sejam atribuídos mais significados e sentidos aos conteúdos (THIESEN, 2008).

A interdisciplinaridade se baseia no conceito de que os conhecimentos são interdependentes e, consequentemente, interativos, portanto, um método educativo não pode ser adotado de forma fragmentada, pois dificultaria a compreensão dessas redes complexas. Nesse sentido, os indivíduos "não aprendem apenas usando a razão, o intelecto, mas também a intuição, as sensações, as emoções e os sentimentos" (THIESEN, 2008, p. 552). Para De 
Marco (2015), a interdisciplinaridade diz respeito não somente aos conhecimentos, mas também aos demais espaços da instituição escolar, não só os considerados "pedagógicos" como as salas de aula, as quadras, os laboratórios. As propostas pedagógicas podem também ser realizadas em outros espaços como refeitório, corredores, pátio, parques, entre outros que estejam disponíveis em cada instituição.

Embora em um dos principais documentos norteadores da educação infantil, as Diretrizes Curriculares Nacionais para a Educação Infantil - DCNEI (BRASIL, 2010), não conste o termo "Educação Física", o movimento consta em seus princípios. Nesse sentido, sob a ótica da cultura corporal, na qual a expressão corporal é entendida como linguagem, é que defendemos a presença do professor de Educação Física na educação infantil, desde que participe do cuidado e da educação das crianças, de forma integrada com a equipe pedagógica. Lembramos que, em 15 de dezembro de 2017, foi homologada a Base Nacional Comum Curricular. Obviamente, as orientações pedagógicas deste documento para a educação infantil ainda estão sendo conhecidas e assimiladas pelos profissionais de instituições de educação infantil brasileiras, razão pela qual fizemos referência às DCNEI (BRASIL, 2010).

A Educação Física, nesse nível de ensino, deve ser orientada para educar a compreensão e o domínio das manifestações e práticas culturais construídas socialmente e valorizar e sistematizar "o movimento corporal da criança, no seu processo de apropriação da cultura e na construção do seu pensamento" (GARANHANI, 2002, p. 108).

Dentre as inúmeras possibilidades, gostaríamos neste estudo de nos aproximar das práticas corporais relacionadas com a expressão por meio do movimento, especificamente por meio do circo, ${ }^{1}$ buscando que o aluno possa vivenciar, explorar e entender as manifestações artístico-corporais, seu próprio corpo, suas possibilidades e o seu potencial comunicador. Como destacam Bortoleto, Pinheiro e Prodócimo (2011), o circo forma parte da nossa história e da nossa cultura. Além disso, o circo tem um forte apelo emocional, pois quase sempre está associado às manifestações de alegria, fato este que indubitavelmente é motivador para as crianças.

É interessante observar como os pequenos apresentam um amplo imaginário circense quando questionados. Dessa forma, como destaca Ontañón Barragan, podemos constatar que:

Mesmo por meio dos olhos de uma criança, percebemos que o circo reúne uma infinidade de significados e interpretações, mas uma coisa é certa: de uma forma ou de outra, se encontra presente no imaginário das pessoas. O circo possui uma idiossincrasia que o caracteriza, um espetáculo vivo que há séculos passou por bairros, vilarejos ou cidades, visitando quase todos os países e todos os continentes. Um espetáculo corporal, visual e sensível que procura incessantemente somar novas linguagens e diferentes elementos culturais, permeando nossa sociedade com simbolismos que certamente podem contribuir com o processo educativo na escola (ONTAÑóN BARRAGAN, 2016a, p. 26).

Como a autora destaca, é comum encontrarmos o circo nos desenhos, contos, brinquedos e nas diversas referências que compõem o universo infantil. No entanto, ao pesquisar conhecimentos abordados por currículos e projetos educativos, notamos que essa arte rara vez é abordada.

Se consultarmos as DCNEI (BRASIL, 2010), encontraremos três princípios que devem ser respeitados para a elaboração de uma proposta pedagógica de educação infantil:

\footnotetext{
${ }^{1}$ Nesta pesquisa, adotamos o termo circo e atividades circenses, entendendo-as como representação das possibilidades de ação, de agir, que se encaixam dentro da linguagem circense, considerando, por exemplo, como destaca Ontañón (2016), os malabares, a acrobacia ou os equilíbrios sobre objetos como diferentes atividades circenses.
} 
éticos, políticos e estéticos. Os éticos dizem respeito à autonomia, à responsabilidade, à solidariedade, tanto ao meio ambiente quanto às diferentes culturas, identidades e singularidades. Os princípios políticos tratam da cidadania, do exercício da criticidade e do respeito à ordem democrática. E os estéticos, "da sensibilidade, da criatividade, da ludicidade e da liberdade de expressão nas diversas manifestações artísticas e culturais" (BRASIL, 2010, p. 16).

Assim sendo, entendemos que o circo, por se configurar como uma manifestação artística e cultural, respeita o princípio estético das DCNEI, de liberdade de expressão nas diversas manifestações artísticas. Ao mesmo tempo em que permite desenvolver noções de valores sociais nas crianças, constituindo relevante tema a ser inserido na educação infantil.

Neste sentido, como destacam Duprat e Perez-Gallardo, o circo:

[...] constitui-se como parte integrante da produção cultural e artística. Ao longo de diversos séculos, ele influenciou modos de produzir, modos de agir e modos de fazer arte, caracterizando-se como um fenômeno sócio-cultural (DUPRAT; PEREZGALLARDO, 2010, p. 55).

Além disso, depois que os saberes circenses extrapolaram o ambiente da lona circense, atingindo outros ambientes e tendo outras finalidades que não a produção de um espetáculo, mas também para o lazer, a formação social ou o condicionamento físico, entre outros, houve algumas adaptações pedagógicas, técnicas e também estéticas, que permitiram que esse conhecimento começasse a ser introduzido e difundido em aulas de Educação Física escolar (ONTAÑÓN BARRAGAN; BORTOLETO; SILVA, 2013). De acordo com Bortoleto, Pinheiro e Prodócimo (2011), esse fato caracteriza o reconhecimento desse saber como patrimônio cultural.

Sendo o circo reconhecido como patrimônio cultural, e o currículo, segundo as Diretrizes, definido como:

Conjunto de práticas que buscam articular as experiências e os saberes das crianças com os conhecimentos que fazem parte do patrimônio cultural, artístico, ambiental, científico e tecnológico, de modo a promover o desenvolvimento integral de crianças [...] (BRASIL, 2010, p. 12).

Encontra-se aqui mais uma justificativa para a utilização desse tema na educação infantil, pois se coaduna com o que as DCNEI (BRASIL, 2010) definem como "currículo".

Ontañón, Duprat e Bortoleto (2012) realizaram estudo bibliográfico sobre as atividades circenses no âmbito escolar. Na maioria das produções encontradas, o objetivo foi o de organizar um modelo de ensino de uma modalidade circense, com maior destaque ao ensino de malabares, fato esse justificado por não oferecer grande risco e nem serem necessários materiais caros, além de acrobacia e perna de pau. Há, também, um grande número de produções que defendem a utilização das atividades circenses na Educação Física por ser um conteúdo inovador e que busca subsídios para justificar sua inclusão no componente curricular, seja do ponto de vista da cultura corporal ou do tecnicismo (DUPRAT; PEREZ-GALLARDO, 2010; INVERNÓ, 2003). Até a década de 1990, os estudos focavam-se principalmente no aprimoramento técnico de uma única modalidade. Foi a partir desse período, devido às concepções teóricas que foram desenvolvidas, que o ensino de atividades circenses ganhou um novo foco, "enquanto possibilidade de desenvolvimento da expressão corporal, reconhecendo sua lógica artística e, assim, destacando aspectos como a criatividade e a comunicação corporal (não verbal)" (ONTAÑÓN BARRAGAN, 2012, p.51).

Bortoleto, Pinheiro e Prodócimo explicitam ainda dois motivos para a inserção das atividades circenses em ambientes educativos: 
Em síntese, nos apoiamos em duas grandes justificativas quando defendemos a inserção das atividades circenses em ambientes educativos: a primeira diz respeito à arte do circo, enquanto parte de nossa história e nossa cultura; e também no potencial lúdico, estético, motor e educativo que essas atividades possuem e que podem contribuir na formação de nossos alunos (BORTOLETO; PINHEIRO; PRODÓCIMO, 2011, p. 14).

Compartilhamos a afirmação de que, na educação infantil, devem prevalecer o lúdico e a brincadeira, pois esse é o mundo das crianças pequenas, o mundo da fantasia e do faz de conta (SIMON; KUNZ, 2014). Tendo em vista o potencial lúdico do circo, pode-se pensar: que criança não gostaria de ser o trapezista, ou o equilibrista ou o palhaço?

Assim, desenvolvendo esta linha de raciocínio, buscamos nesta pesquisa, a partir do referencial e de recursos pedagógicos da Educação Física, apresentar uma proposta de atividades no âmbito da educação infantil, no intuito de demonstrar as possibilidades de intervenção do professor de Educação Física neste nível da educação básica, sob a perspectiva da interdisciplinaridade.

\section{Método}

De acordo com Neves (1996), o método de pesquisa empregado foi de natureza qualitativa, pelo seu caráter descritivo de uma proposta pedagógica interdisciplinar ancorada nas atividades circenses que respeita a identidade e a especificidade das crianças de 4 e 5 anos da educação infantil, sendo também do tipo documental, pois buscou estabelecer relações baseadas em fontes diversas, tais como legislação, livros e artigos, entre a Educação Física e a educação infantil, por meio de conteúdo da cultura corporal, neste caso, o circo.

Um dos procedimentos metodológicos adotados consistiu numa revisão bibliográfica inicial, de forma a reunir produções acadêmicas nas quais houvesse relação entre as atividades circenses e o ambiente escolar, visando embasar teoricamente esta proposta. Foram pesquisadas publicações nos indexadores Portal CAPES de Periódicos e LILACS, além de consultas diretas às bases de dados de revistas brasileiras de Educação Física, ranqueadas no sistema Qualis/CAPES 2014, nas categorias A2, B1 e B2. Para todas as buscas, utilizamos as palavras-chave: atividades circenses e/ou circo, e apenas as publicações que tinham relação com o ambiente escolar foram selecionadas. Além dessas publicações, buscamos publicações de artigos e livros no acervo do Grupo de Estudos e Pesquisa das Artes Circenses (Circus), ${ }^{2}$ com sede na própria Faculdade de Educação Física da UNICAMP, o qual desenvolve investigações sobre o circo e suas relações com a Educação Física. Foi consultado também o Sistema de Bibliotecas da UNICAMP - SBU.

\section{Projeto}

\section{Mapeamento/ Diagnóstico}

Propomos que este projeto seja iniciado com a fase de mapeamento/diagnóstico, por meio do diálogo com as crianças com questionamentos, buscando identificar quais conhecimentos do circo elas dominam. Questionamentos como: o que é circo; o que tem no circo; se elas já foram ao circo; se já brincaram alguma vez de circo; o que nós fazemos quando vamos ao circo. Ao longo desse diálogo, será dada continuidade, buscando identificar quais outros elementos que fazem parte do universo circense as crianças conhecem. Quais personagens do circo elas conhecem; quais personagens presentes no circo que elas mais gostam; qual

\footnotetext{
${ }^{2}$ Para maiores informações: http://www.fef.unicamp.br/fef/posgraduacao/gruposdepesquisa/circus/apresentacao. Acesso em: 20 out. 2017. 
personagem elas gostariam de ser; o que mais tem no circo além dos personagens que aparecem no picadeiro (como o pipoqueiro, as arquibancadas, música, apresentador e outros). É interessante que a professora realize um registro dessas informações, pois, assim, essa documentação se torna "um instrumento pedagógico que auxilia na compreensão das práticas sociais das crianças" (AYOUB, 2001, p.14), que permitirá refletir sobre a prática pedagógica e auxiliará no desenvolvimento do projeto.

Há diversas formas de registro, tanto do professor quanto das crianças, como pastas, cadernos, diários, fichas, portfólios, gravações audiovisuais, fotografias, desenhos e colagens. Para o registro desse mapeamento, a professora pode utilizar um caderno ou diário, com as respostas que surgiram. Esses registros poderão ser feitos também, de forma lúdica e ativa, com as crianças desenhando, pintando e representando os personagens do circo.

Ainda como parte dessa atividade de mapeamento/diagnóstico, propomos a apresentação para as crianças de algumas imagens pré-selecionadas de práticas corporais circenses e de outras práticas com elementos corporais similares, como balé, ginástica artística, ginástica rítmica, aparelhos circenses e outros aparelhos diversos. Por intermédio das imagens, é possível questionar quais dessas podem ser encontradas no circo. Durante esse diálogo, devem-se buscar argumentos do porquê de uma imagem fazer referência ao circo enquanto outra, semelhante, não o faz, por exemplo, uma foto de um artista circense fazendo uma parada de mãos e a de um ginasta. O objetivo dessa atividade é ampliar o nosso conhecimento sobre o que as crianças identificam como parte do universo circense - o figurino, as cores, os formatos, os aparelhos ou outro componente.

Indagando sobre os conhecimentos que as crianças têm sobre personagens e aparelhos presentes no circo, bem como de outros elementos que possam surgir, se torna possível que o conhecimento delas seja ampliado. Para isso, propomos a utilização de um livro infantil com a temática do circo, como sugerimos no ponto seguinte.

\section{Ampliação/intervenção}

A realização das atividades propostas pode ser efetivada em todos os espaços disponíveis da instituição, como refeitório, corredores, pátio, não apenas nos considerados "pedagógicos", pois a interdisciplinaridade também diz respeito aos espaços (DE MARCO, 2015).

Há, na literatura infantil, expressiva quantidade de livros que apresentam o universo circense, por serem orientados às crianças pequenas, e de grande atrativo visual. Destes, indicamos três livros: $O$ circo chegou! (BEDICKS; BORTOLETO, 2015), O circo (DIAS, 2014) e Circolândia (EGEA; VIANNA, 2014).

O circo chegou! apresenta "o interior do espetáculo circense", tanto os personagens que ficam sob as luzes do espetáculo, como palhaços, trapezistas, malabaristas, mágico, um acrobata disfarçado (que foram inspirados em personagens reais que compõem o Grupo Circus), como os que não estão sob as luzes, mas que compõem o universo circense, como o pipoqueiro e a banda. Outros elementos podem ser explorados, como os figurinos coloridos e a alegria expressa nos personagens.

Nesse livro, assim como em Circolândia, é interessante o conhecimento do contexto do circo, que pode ser desenvolvido por meio de alguns de seus personagens, como é o caso do acrobata disfarçado de macaco. Nesse ponto, podemos dialogar com as crianças, se elas já foram a algum circo em que havia animais; contar às crianças que, na história do circo, houve um período em que cavalos e outros animais adestrados faziam parte do espetáculo (DUPRAT, 2007); questionar se alguma delas já viu algum animal no circo. Esse diálogo nos permite tocar nos conteúdos transversais, dialogando de maneira critica com as crianças sobre o respeito aos animais e o cuidado com eles, indagando sobre o que elas pensam da presença 
dos animais em circos, mas também em outros espaços como rodeios, zoológicos, laboratórios, etc.

Circolândia é um livro de conotação pedagógica. Ao longo de sua narrativa, traz conhecimentos da cultura circense. É um livro interessante, que aborda aspectos históricos, traz exemplos de atividades para a vivência de algumas atividades circenses, como malabarismo, mágica e equilibrismo, além de propor a construção de alguns materiais.

A forma de utilização dos livros fica a critério da professora, de realizar toda a leitura de uma só vez, de forma contínua, ou realizar a leitura de forma fragmentada, explorando os elementos e os personagens aos poucos. Nossa proposta sugere que as leituras, tanto a do livro $O$ circo chegou! quanto a de $O$ circo, sejam realizadas de forma contínua, pois são livros de leitura breve, portanto, se torna mais fácil manter a atenção das crianças, mas que também sejam retomadas quando alguns dos personagens presentes neles forem sendo desenvolvidos. Circolândia, por ser um livro maior e mais denso, apresenta dificuldade para que as crianças mantenham a atenção se a leitura for contínua. Além disso, por abordar aspectos históricos, prevemos que possa ser melhor explorado quando apresentado em momentos diferentes.

A sugestão para a utilização dos livros é no sentido de se ter um apoio para o desenvolvimento da atividade pedagógica e não sua base, uma vez que não substitui o aprofundamento sobre as atividades circenses, sua cultura e sua história em outras fontes.

As respostas que surgiram pelo diálogo com as crianças, por exemplo, sobre quais personagens elas mais gostam, ou qual dos personagens elas gostariam de ser, auxiliarão na organização das situações de aprendizagens que serão elaboradas na etapa seguinte e deverão ser exploradas de acordo com o interesse demonstrado pelas crianças.

\section{Jogos diversos (sobre o contexto)}

A brincadeira popular "Mamãe da Rua" pode ser contextualizada na temática circense para a brincadeira "Dono do Picadeiro". Nessa versão, haverá dois espaços para a brincadeira, delimitados no chão por um desenho com giz - o picadeiro e a arquibancada -, e dois personagens - o dono do picadeiro e os artistas.

\section{Figura 1- Esquema dos espaços para a brincadeira "Dono do Picadeiro"}

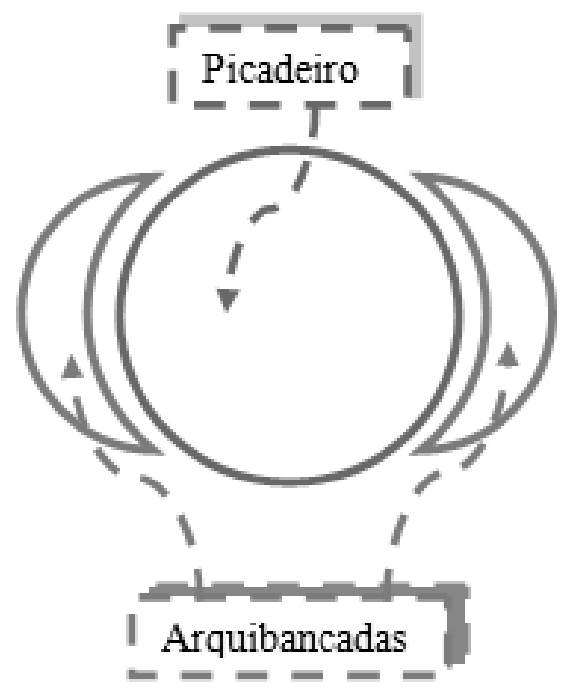

Fonte: Autoria própria. 
A brincadeira se inicia com uma criança no centro do picadeiro, que é o dono do picadeiro, e os demais artistas ao redor, na arquibancada. Ao sinal da professora ou do dono do picadeiro, os artistas deverão trocar de lado da arquibancada, passando pelo centro do picadeiro; o dono do picadeiro deverá tentar tocar em quantos artistas conseguir. Os artistas que forem tocados tomarão o lugar do dono do picadeiro. Antes que uma nova rodada se inicie, os artistas que foram pegos na rodada anterior deverão fazer uma apresentação para todos.

O conteúdo dessa apresentação poderá ser escolhido de diversas formas. A professora poderá deixar à disposição diversos materiais que já foram previamente apresentados e explorados pelas crianças, para que elas escolham quais materiais irão utilizar na apresentação, ou ainda limitar qual ou quais serão os materiais que estarão à disposição das crianças. Outra possibilidade é que, em momentos anteriores à brincadeira, quando da exploração dos materiais de manipulação, das acrobacias, dos equilíbrios e de outros conteúdos, as crianças sejam fotografadas realizando determinadas experimentações. Por exemplo, equilibrando blocos sobre a cabeça, ou pontes com os pés na parede, ou sobre a "corda-bamba"; estas ações realizadas poderão ser utilizadas nessa brincadeira "Dono do Picadeiro". Ao terminar uma rodada, os artistas que foram pegos e que se tornaram os donos do picadeiro escolherão ou sortearão uma das fotos para ser reproduzida antes que se inicie uma nova rodada.

\section{Manipulações}

Provavelmente, o material mais conhecido de malabares são as bolinhas. No entanto, um material interessante de ser abordado nas manipulações, ainda mais na educação infantil, é o lenço ou tule. Assim o defendem vários estudiosos da área como Bortoleto et al. (2008), Ontañón Barragan (2016b) ou Rodrigues (2007). O tule, pela sua estrutura física, tem um tempo de queda maior, o que possibilita que a criança tenha maior tempo para reagir e poder manipulá-lo com facilidade. Existe, inclusive, um DVD elaborado pelo Grupo Circus que aborda a pedagogia dos malabares com tule e que está disponível na internet. ${ }^{3}$

Uma atividade possível de realizar com esse material é o jogo "Pega-Gelo", que poderá ser contextualizado para essa unidade pedagógica, sendo denominado de "PegaMalabarista". Todas as crianças terão uma bolinha ou um tule. Uma delas, que será o malabarista-pegador, terá uma bolinha de meia. O objetivo do jogo consiste em que o malabaristapegador tente pegar os demais malabaristas lançando sua bolinha. Ao ser tocado pela bolinha, o malabarista-fugitivo deverá ficar parado no mesmo local e manipular sua bolinha, enquanto aguarda que outro malabarista-fugitivo se aproxime e então eles troquem de bolinhas, fazendo um lançamento entre si.

A complexidade do jogo pode aumentar, trocando a forma como os malabaristasfugitivos lançarão suas bolinhas/tules entre si, que pode ser por baixo da perna, pelas costas, ou na forma como recepcionarão a bolinha/tule, dando um giro antes, batendo duas palmas antes, na posição sentada, deitada, entre outras posturas que poderão ser elaboradas pelas próprias crianças. Até o material escolhido altera a complexidade do jogo, tendo em vista que o tule permite maior tempo de reação, já que ele fica mais tempo no ar, o que facilita sua manipulação, enquanto a bolinha tem um tempo menor de queda, diminuindo o tempo de reação, consistindo, portanto, num material com maior dificuldade para manipulação.

Em se tratando de manipulação, sugerimos outra possibilidade de jogo contextualizado, o "Pega-encantado". As crianças dessa faixa etária ainda não compreendem jogos muito complexos, com muitas regras e acúmulo de funções. Por exemplo, ao mesmo tempo em que eu devo fugir, eu posso salvar meu colega que foi pego. Para isso, propomos uma divisão inicial de funções em três personagens: um irá pegar, outro fugir e o terceiro salvar.

\footnotetext{
${ }^{3}$ Link para o DVD Pedagogia dos malabares: <https://www.youtube.com/watch?v=Z5xWeVNWKqA>.
} 
Na prática, o jogo terá três personagens: o malabarista, o coelho e o mágico. E terá duas áreas distintas: o picadeiro e a cartola, que pode ser uma cartola gigante real, de papelão, ou apenas uma área delimitada no chão por um desenho de giz. O malabarista deverá lançar uma bolinha para pegar o coelho, que, ao ser tocado pela bolinha, deverá ficar parado, imitando uma estátua; o mágico deverá salvar o coelho, levando-o até a cartola ou na área referente a ela, caso esteja desenhada no chão.

O jogo poderá ter alguns objetos que colaborem para o faz de conta, como uma cartola gigante de papelão confeccionada em conjunto com as crianças, que poderão participar tanto montando a cartola quanto a decorando, com tintas guache ou lápis de cor. Além da cartola gigante, podem ser confeccionadas cartolas menores para que as crianças as usem durante o jogo; varinhas para os mágicos, com folhas de jornal enroladas, as quais as crianças também podem decorar de acordo com a criatividade, e orelhas de coelho. $\mathrm{O}$ mágico poderá também ter uma palavra mágica para tirar o encanto do coelho.

Para as crianças, é interessante que o jogo tenha um contexto com cenário e histórias. Pois, dessa forma, poderá ser realizado "com mais alegria, empenho e desembaraço pela criança" (SIMON; KUNZ, 2014, p. 387).

É na brincadeira de faz de conta que as crianças estimulam as capacidades de sonhar, devanear e criar - relacionadas, sobretudo, com o pensamento abstrato e capacidades subjetivas. É importante não tolher tais capacidades, mas pelo contrário, oferecer elementos que estimulem a capacidade criativa nas brincadeiras de faz de conta. São atividades que criam oportunidades de transformação às crianças ao se comportarem como animais, personagens de contos, heróis e heroínas, entre outros (SIMON; KUNZ, 2014, p. 388).

Nesse sentido, sugerimos o seguinte enredo:

O malabarista viu que os coelhinhos do mágico estavam fugindo da cartola. Ele tentou correr atrás deles, mas eles eram muito rápidos. Então, ele teve a grande ideia: pegar uma bolinha de malabares, encantá-la com uma mágica, para que, quando a bolinha tocasse no coelho, ele virasse uma estátua. E, assim, o mágico poderia vir com sua varinha, tirar o encanto e levá-lo de volta à cartola!

\section{Avaliação}

Segundo a DCNEI, a avaliação na educação infantil tem a função de acompanhar o trabalho pedagógico, bem como o desenvolvimento das crianças, e não pode ocorrer com o objetivo de seleção, promoção ou classificação. A avaliação da criança pequena deve ser vista com relação a ela mesma e não comparada com padrões ou com outras crianças (DE MAR$\mathrm{CO}, 2015)$ e pode ocorrer por meio de registros, tanto dos professores quanto das crianças e dos demais agentes participantes do processo educativo, registros esses que poderão ser utilizados para a elaboração de uma documentação destinada aos familiares das crianças para "conhecer o trabalho institucional e os processos de desenvolvimento e aprendizagem da criança" (BRASIL, 2010, p. 29).

A avaliação desse projeto interdisciplinar, do trabalho pedagógico, será baseada nos registros dos adultos, elaborados a partir da "observação critica e criativa das atividades, das brincadeiras e interações das crianças no cotidiano" (BRASIL, 2010, p. 29), além dos registros produzidos pelas crianças. A socialização desses registros nas reuniões pedagógicas permitirá a avaliação sobre o processo educativo mediado pelo diálogo com os demais agentes do processo, bem como a realização de correções quando necessário. 
A duração para o desenvolvimento desta proposta pedagógica dependerá muito das características ambientais, dos tipos de recursos materiais disponíveis e do envolvimento da equipe pedagógica e da disponibilidade das crianças participantes. A priori, avaliamos que, no primeiro mês, pode ser feito o mapeamento/diagnóstico. A partir deste, é possível elaborar o planejamento inicial para ser realizado nos meses seguintes do semestre, o qual deverá ser aperfeiçoado e adaptado de acordo com as características do grupo.

\section{Considerações finais}

A educação infantil deve assegurar o caráter de educação integral, garantindo a unicidade entre as dimensões expressiva, motora, afetiva, cognitiva, linguística, ética, estética e sociocultural das crianças. Uma proposta interdisciplinar contempla essa educação integral na medida em que compreende que os conhecimentos são interdependentes e interativos e, com o desenvolvimento de conteúdos de forma integrada entre professoras especialistas e professoras generalistas, é possível atender a esses princípios nas interações com crianças da educação infantil.

Um processo educativo interdisciplinar que busca romper com a especialização permite a formação total do ser humano, inserido em sua realidade e como agente das mudanças do mundo, possibilitando que sejam atribuídos mais significados e sentidos aos conteúdos (THIESEN, 2008). Assim, a Educação Física na educação infantil deve estar integrada à proposta pedagógica e deve educar a compreensão e o domínio das manifestações e práticas culturais construídas socialmente (GARANHANI, 2002). As atividades circenses, por configurarem uma manifestação artística e cultural, respeitam o princípio estético das DCNEI, de liberdade de expressão nas diversas manifestações artísticas, ao mesmo tempo em que permitem desenvolver noções de valores sociais nas crianças, constituindo-se em um relevante tema a ser inserido na educação infantil.

Foram apresentadas neste texto algumas possibilidades de trabalho pedagógico com as atividades circenses no âmbito da educação infantil. Um planejamento pedagógico elaborado de maneira interdisciplinar, entre professoras especialistas, de Educação Física, de outras áreas (música, artes, dança, educação ambiental), com as professoras generalistas (pedagogas), demonstrando que uma proposta desta natureza pode ampliar significativamente as possibilidades de estratégias pedagógicas. No entanto, sabemos que o projeto deve ser pensado, planejado, contextualizado e posteriormente refletido, de forma coletiva, entre os demais atores do processo educativo, tornando possível rever e reavaliar sempre os sucessos e insucessos do planejamento pedagógico colocado em prática, ou seja, a partir de uma dinâmica que é própria da educação.

\section{Referências}

AYOUB, E. Reflexões sobre a educação física na educação infantil. Revista Paulista de Educação Física, São Paulo, supl. 4, p. 53-60, 2001.

BEDICKS, M. G. BORTOLETO, M. A. C. O circo chegou! Campinas: FEF/UNICAMP, 2015.

BORTOLETO, M. A. C. (Org.). Introdução à pedagogia das atividades circenses. Jundiaí: Editora Fontoura, 2008. v.1.

; PINHEIRO, H. G. G.; PRODÓCIMO, E. Jogando com o Circo. Várzea Paulista: Fontoura, 2011. 
BRASIL. MEC, SEB. Diretrizes Curriculares Nacionais para a Educação Infantil. Brasília: MEC, SEB, 2010.

CERISARA, A. B. Educar e cuidar: por onde anda a educação infantil? Perspectiva, Florianópolis, v. 17, n. especial, p. 11-21, jul./dez. 1999. Disponível em <https://periodicos.ufsc.br/index.php/perspectiva/article/viewFile/10539/10082>. Acesso em: 14 abr. 2016.

COLETIVO DE AUTORES. Metodologia do ensino de educação física. São Paulo: Cortez, 1992. (Coleção Magistério $2^{\circ}$ grau. Série Formação do professor).

DE MARCO, A. Espaço pedagógico interdisciplinar para estimulação integral de crianças na educação infantil. In: SOUZA, E. R. et al. (Org.). Educação Física, lazer e saúde: interfaces ao desenvolvimento humano. Florianópolis: Editora da UDESC, 2015.

Circo, desenvolvimento e educação infantil. In: BORTOLETO, M. A.; Teresa ONTAÑ̃́N BARRAGÁN, T.; SILVA, E. (Org.) Circo: horizontes educativos. Campinas: Autores Associados, 2016.

DIAS, V. L. O circo. São Paulo: Cortez, 2014.

DUPRAT, R. M. Atividades circenses: possibilidades e perspectivas para a Educação Física escolar. 2007. 122 f. Dissertação (Mestrado em Educação Física) - Faculdade de Educação Física, Universidade Estadual de Campinas, Campinas. 2007.

DUPRAT, R. M.; PEREZ-GALLARDO, J. Artes circenses no âmbito escolar. Unijuí, SP: Ed. Unijuí, 2010.

JOGOS de malabares "Lenços". Elaborado em parceria com a empresa JR Malabaris. 2010. Coleção Pedagogia das Atividades Circenses. 1 DVD didático.

EGEA, R. F. V.; VIANNA, R. Circolândia. São Paulo: Moderna, 2014.

GARANHANI, M. C. A educação física na escolarização da pequena infância. Revista Pensar a Prática, v. 5, p. 106-122, jul./jun. 2002. Disponível em $<$ https://revistas.ufg.emnuvens.com.br/fef/article/view/49/46>. Acesso em: 14 abr. 2016.

INVERNÓ, J. Circo y educación física, otra forma de aprender. Barcelona: INDE Publicaciones, 2003.

NEVES, J. L. Pesquisa qualitativa: características, usos e possibilidades. Cadernos de Pesquisas em Administração, São Paulo, v. 1, n. 3, $2^{\circ}$ sem. 1996. Disponível em: <http://www.unisc.br/portal/upload/com_arquivo/pesquisa_qualitativa_caracteristicas_usos_e _possibilidades.pdf $>$. Acesso em: 3 maio 2016.

ONTAÑÓN BARRAGAN, T. Atividades circenses na educação física escolar: equilíbrios e desequilíbrios pedagógicos. 2012. 142 f. Dissertação (Mestrado em Educação Física) - Faculdade de Educação Física, Universidade Estadual de Campinas, Campinas, 2012. 
O circo e sua contribuição para a educação escolar. In: BORTOLETO, M. A. C.; ONTAÑON BARRAGÁN, T.; SILVA, E. (Org.). Circo: horizontes educativos. Campinas, SP.: Autores Associados, 2016a. v. 1, p. 189-208.

. Circo na escola: por uma educação corporal, estética e artística. 2016. Tese (Doutorado em Educação Física) - Faculdade de Educação Física da Universidade Estadual de Campinas, 2016b.

ONTAÑÓN, T.; BORTOLETO, M. A. C.; SILVA, E. Educación corporal y estética: las actividades circenses como contenido de la educación física. Revista Iberoamericana de Educación, Madrid, n.62, p. 233-243, 2013.

.; DUPRAT, R. M.; BORTOLETO, M. A. C. Educação Física e atividades circenses: o estado da arte. Revista Movimento, Porto Alegre, v. 18, n. 2, abr./jun. 2012.

RODRIGUES, L. H. Representação das atividades circenses na escola. Dissertação. 2007. Dissertação (Mestrado em Educação Física)-Centro de Educação Física, Fisioterapia e Desportos, Universidade de Estado de Santa Catarina, Florianópolis, 2007.

SANTIN, S. Educação Física: uma abordagem filosófica da corporeidade. 2. ed. Unijuí: Ed. Unijuí, 2003.

SIMON, H. S.; KUNZ, E. O brincar como diálogo/pergunta e não como resposta à prática pedagógica. Revista Movimento, Porto Alegre, v. 20, n. 1, p. 375-394, jan./mar. 2014. Disponível em <http://www.seer.ufrgs.br/index.php/Movimento/article/view/39749/28357>. Acesso em: 22 mar. 2016.

THIESEN, J. D. A interdisciplinaridade como um movimento articulador no processo ensinoaprendizagem. Revista Brasileira de Educação, v. 13, n. 39, p. 545-554, set./dez. 2008. Disponível em: 〈http://www.scielo.br/pdf/rbedu/v13n39/10.pdf> . Acesso em: 12 maio 2016.

Endereço para correspondência:

laismcorsi@gmail.com

Laís Marconato Corsi

Universidade Estadual de Campinas,

Faculdade de Educação Física, Departamento de Educação Física e Humanidades.

Cidade Universitária Zeferino Vaz

Barão Geraldo

13083970 - Campinas, SP - Brasil 